Research Article

\title{
Fragmentation Pattern and Removal Mechanism of Concrete Subjected to Abrasive Water Jet Impact
}

\author{
Jialiang Liu $\mathbb{D}^{1,2}$ Yujie Zhu $\mathbb{D}^{1,2}$ Yongzhi Xue $\mathbb{D}^{1},{ }^{3}$ and Hao Sun $\mathbb{D}^{1,2}$ \\ ${ }^{1}$ State Key Laboratory of Mountain Bridge and Tunnel Engineering, Chongqing Jiaotong University, Chongqing 400074, China \\ ${ }^{2}$ Civil Engineering College, Chongqing Jiaotong University, Chongqing 400074, China \\ ${ }^{3}$ School of Mechanical and Automotive Engineering, South China University of Technology, Guangzhou, \\ Guangdong 510641, China \\ Correspondence should be addressed to Yongzhi Xue; xyzxyz0601@163.com
}

Received 30 December 2020; Revised 28 February 2021; Accepted 10 March 2021; Published 24 March 2021

Academic Editor: Jun Liu

Copyright (C) 2021 Jialiang Liu et al. This is an open access article distributed under the Creative Commons Attribution License, which permits unrestricted use, distribution, and reproduction in any medium, provided the original work is properly cited.

\begin{abstract}
Abrasive water jet (AWJ) breaking technology is suitable for the maintenance and repair of concrete structures, generating minimal dust, low tool wear, and no vibrations or selective destruction. The failure features and mechanisms of concrete subjected to AWJ impact are fundamental issues of AWJ breaking technology, which are also related to the safety and quality of engineering construction. Based on computed tomography (CT), scanning electron microscopy (SEM), and image processing technology, this paper studied the fragmentation pattern and removal mechanism of concrete under AWJ impact. The general failure characteristics and crack propagation law of concrete subjected to AWJ impact were described through AWJ impact concrete tests. The spatial distribution of damage in concrete subjected to AWJ impact can be divided into the intensive action zone, the transition zone, and the weak action zone. The removal mechanism of AWJ was discussed by comparing the impact performance of a pure water jet (PWJ) system. The results indicate that abrasive particles can cause cliff-shaped fracture and lip-shaped distortion in the aggregate part and flat fracture surface in the matrix part. There is no obvious crack in the interfacial transition zone (ITZ) due to the weakening of the water wedge effect.
\end{abstract}

\section{Introduction}

Concrete is the most widely used building material due to its good plasticity, low production cost, and high durability. Nevertheless, due to unreasonable design and construction, there are often some primitive defects in concrete materials. When facing weathering, corrosion, repeated expansion and contraction, and external impact, it is easy for cracks, holes, edge damage, arch camber, and other defects to occur as time goes by, threatening the stability and safety of the concrete structures [1]. It is foreseeable that the repair and maintenance of infrastructures are placing an increasing burden on the government, so safe and efficient repair technologies are urgently needed.

In the process of structure repair, it often needs to remove the damaged concrete and recast the new concrete, without harm to the steel rebar. Traditional mechanical methods have difficulty distinguishing between concrete and steel bar while carrying out selective destruction, causing the easy distortion and looseness of steel rebar. Moreover, the strong impact forces generated by traditional mechanical tools may further damage nearby concrete and create new quality hazards. Dust and tool wear are also challenges.

Hydraulic demolition relying on abrasive water jet (AWJ) impact can split, peel, and transport the damaged concrete through high-energy-density water flow, evading the disadvantages of traditional mechanical crushing technology by use of its unique destruction mode $[2,3]$. The AWJ method can achieve the purpose of removing concrete while protecting the steel bars by adjusting the impact parameters, which provides vast application prospects in the construction repair field [4]. Nevertheless, for the demolition of special stressed structures, especially for the emergency removal of structures after disasters, the crushing accuracy 
and safety of AWJ technology must be further improved. Therefore, it is necessary to conduct in-depth studies on the general mechanical behaviors of concrete materials under water jet impact, such as the fragmentation patterns and removal mechanisms.

Studies have been carried out in recent years to explore the fragmentation of different materials, such as rock, impacted by water jets. For numerical simulations, Shet and Deng [5] used the finite element method to research the effect of the jet hole position and jet pressure on the highpressure water jet cutting of orthogonal metals. Lu et al. [6] used theoretical analysis and numerical simulations to analyse the impact and vibration effects of a high-pressure pulsed water jet on coal. Wu et al. [7] developed a twodimensional SPH-FEM/DEM coupled model based on LSDYNA software to investigate the rock breaking behavior under water jet impact, where the SPH method was adopted to model the water jets and the FEM/DEM method was used to simulate the rock breaking response. Ren et al. [8] established a numerical model of particle water jet impacting rock by using the SPH-FEM coupling algorithm and studied the damage mechanism of particle water jet coupled impact. $\mathrm{Wu}$ et al. [9] built a thermal-fluid-solid coupled model to investigate the distribution of thermal stress in granite subjected to liquid nitrogen jet impact.

For experimental research studies, Arola and Ramulu [10] studied the effect of material properties on the surface integrity and texture of metals subjected to AWJ machining by the exploration of the microstructure and microhardness. By using orthogonal analysis, $\mathrm{Hu}$ et al. [11] revealed the cutting mechanism by measuring the cutting depth and studied the effect of pump pressure, nozzle transverse velocity, and stand-off distance on the high-pressure water jet cutting of rubber materials. Bowden and Brunton [12] used a high-speed camera to observe the deformation of solids and study the situation of liquids during the water jet impact process. Kovacevic et al. [13] monitored the acoustic emission (AE) signals and punching depth during water jet drilling to study the removal mechanism of ceramics. Hocheng and Weng [14] conducted a regression analysis to study the relationship between concrete material loss and impact parameters under a submerged jet, such as the incident angle, stand-off distance, and hydraulic pressure. Momber [15] analysed the deformation and fracture of four rock materials and two cementitious materials under the impingement of simulated liquid drops and pointed out the difference between the removal mechanisms of soft materials and hard materials. Dehkhoda and Hood [16] developed an analysis of the internal failure of rock samples with and without applying pulsed water jet impact by measuring the wave-attenuation capacity. The pulse lengths and the pulsation frequencies of the jets were found to cooperate in developing the internal damage. The above simulation and experimental studies focused on the failure law and fracture mechanism of the water jet breaking of elastic, elastic-plastic, and brittle materials, which provides a foundation for exploring the failure characteristics and removal mechanism of AWJ impacting concrete materials.
Computed tomography (CT) is effective in detecting the distribution of cracks in structures under nondestructive conditions while scanning electron microscopy (SEM) is helpful to obtain the fracture mechanism of structures by magnifying the microscopic morphology of the structures $[17,18]$. Fan et al. [19-21] analysed effects on microproperties of granite by observing the volumetric porosity of granite, investigated the spatial gradient distributions of thermal shock-induced damage, and studied the three-dimensional spatial distribution of microdefects of granite induced by thermal cycles. Sun et al. [22] explored quantitatively the evolutions of visible fractures, invisible fractures in CT slices, average density, and heterogeneity of the soil and rock mixture during the uniaxial compression process. By the SEM technology, Fan et al. [23] evaluated the thermal effects on the geophysical properties of granite. Blonskaya et al. [24] observed the latent ion tracks in semicrystalline polymers by scanning electron microscopy. Zhao et al. [25] revealed the micromechanism of the effect of strain rates on rock mechanical behaviors. Bera et al. [26] revealed the microstructure of Berea sandstone by combining CT and SEM, reconstructed its three-dimensional pore space model, and characterized the Berea sandstone specimen by the calculation of pore-structure volumes and determination of porosity values. Remi et al. [27] studied the in situ tension of self-healing matrix composites using CT and SEM and analysed the influence of the oxide in the cracks on the tensile property. Heng et al. [28] used CT to observe the internal structure of rock, the three-dimensional morphology of fracture pits, and the distribution of cracks and further used SEM to study the microstructure of the fracture section.

In summary, this paper attempts to investigate the fragmentation pattern and removal mechanism of concrete subjected to AWJ impact from macroscopic and microscopic perspectives, respectively. It discusses the failure characteristics, crack extension law, and spatial distribution of damage by observing the external fragmentation pattern of concrete and CT scans. Furthermore, this paper explores the removal mechanism of AWJ by comparing the impact performance of pure water jet (PWJ) with SEM scans. The results can provide important theoretical bases for understanding the development law and derivation mechanism of microcracks in concrete under the impact of AWJ, which can help the technology be better applied in the maintenance and repair of concrete structures as well as in emergency demolition.

\section{Experiments}

2.1. Devices and Parameters Settings. The AWJ machine applied in the impact experiment was a Shanghai Jinjian JJI42 $* 1313$ system, which is a high accuracy device equipped with a PC controller, alternating current (AC) servo system, and linear straight rail, and its working pressure is in the range of $70 \mathrm{MPa}$ to $420 \mathrm{MPa}$. In this paper, the parameters adopted in the impact experiment are listed in Table 1 based on practical experience and material strength. 
TABLE 1: Impact parameters applied in the experiments.

\begin{tabular}{lc}
\hline Parameters & Value \\
\hline Target distance & $5 \mathrm{~mm}$ \\
Outlet diameter of nozzle & $1.02 \mathrm{~mm}$ \\
Water flow & $3.0 \mathrm{~L} / \mathrm{min}$ \\
Impact angle & $90^{\circ}$ \\
Impact time & $30 \mathrm{~s}$ \\
Pump pressure & $270 \mathrm{MPa}$ \\
Abrasive flow & $0.6 \mathrm{~g} / \mathrm{s}$ \\
Abrasive type & Sandblasted garnet \\
Abrasive density & $4 \mathrm{~g} / \mathrm{cm}^{3}$ \\
Abrasive hardness & 7.6 \\
Surface roughness of abrasive & $30-80 \mathrm{microns}$ \\
\hline
\end{tabular}

The CT device is a 16-slice spiral Siemens SOMATOM scope, which can achieve a 360-degree full-scan and is equipped with an X-ray digital imaging system consisting of a Rico DR-NOVA system, microplate detectors, high-performance microfocal tubes, and fly focus technology to ensure a high-quality image. And the CT device has a resolution of $0.35 \mathrm{~mm} \times 0.35 \mathrm{~mm}$, and it can realize the scans of the $1530 \mathrm{~mm}$ length and the $0.6-10 \mathrm{~mm}$ thickness.

A Sigma 300 SEM instrument, which has a sophisticated GEMINI optical system with low-voltage imaging capabilities and can realize microscopic imaging, was used in the experiments to study the microscopic morphologies of the fracture sections. A schematic of the experimental system is shown in Figure 1.

2.2. Sample Properties. Because the effect of AWJ on concrete is only in the small range (approximately 20 times jet diameter), the dimension of the concrete specimens used for the experiments was $100 \mathrm{~mm} \times 100 \mathrm{~mm} \times 100 \mathrm{~mm}$. 32.5 Portland cement and river sand of $16-31.5 \mathrm{~mm}$ were selected as fine aggregate, and single-grading gravel of $5-10 \mathrm{~mm}$ was used as the coarse aggregate. The ratio of cement, sand, gravel, and water was $1: 2.39: 4.27: 0.51$, and the age of concrete is 28 days. The strength grade of the concrete was C30. Some mechanical properties of the concrete specimens are presented in Table 2.

\section{The Fragmentation Pattern of the Concrete}

3.1. Failure Characteristics and the Crack Extension Law. To evade the randomness of test results and obtain the general failure characteristics and the crack propagation law of concrete impacted by AWJ, four groups of impact experiments were carried out. Figure 2 shows the failure morphologies of four concrete samples under the same impact parameters. This paper mainly investigates the fragmentation pattern and removal mechanism of concrete subjected to AWJ impact in the maintenance and repair of damaged concrete structures, and therefore, initial defects such as holes were added to make the studied concrete more similar to real damaged concrete.

By analysing the features of the four groups of concrete impacted by AWJ, it can be found that the four crater surfaces were similar to some extent, which was reflected by their irregular shapes due to the random distribution of aggregates, initial defects, and rough crater walls as well as the exposed aggregates. In addition to the highly fractured zone near the crater, the cracks penetrating the impact surface generated near the crater, which caused the macrodamage under the combined action of the shear component and the tensile component of the shock stress wave. Some internal cracks and cracks on the impacted surface propagated to the lateral surface, forming a network of radial cracks and circumferential cracks intersecting each other.

To further explore the crack propagation law, CT scanning was used to detect the internal structure of concrete. Figure 3 shows the CT images of two cross sections of concrete after AWJ impact. The results show that the macrocracks mainly propagated along the interfacial transition zone (ITZ) during the extension process due to its weak mechanical properties. Compared to hardened cement paste, ITZ is more porous and has fewer unhydrated cement particles, a higher $\mathrm{Ca} / \mathrm{Si}$ ratio, and higher $\mathrm{Ca}(\mathrm{OH})_{2}$ contents, and these pores are also the preferential infiltration and splitting zone of high-pressure water [29]. For the most macrocracks propagated along ITZ, the aggregate could keep the integrity, and the undamaged zone of concrete could still retain its strength.

3.2. Spatial Distribution of the Damage. To clarify the spatial distribution characteristics of damage in concrete, this paper took $3 \#$ specimen as an example to carry out a three-dimensional CT scan. Considering that the grey values from the damaged parts, such as cracks and holes, to the undamaged parts in the CT slices are obviously different and the grey value variation can reflect the damage evolution of concrete, this paper performed the binarization and greyscale processing of CT slices. First, these CT slices were divided into $238 \mathrm{px} \times 238 \mathrm{px}$, a total of 91204 pixels. Then, the grey value of each pixel was subtracted to form a $302 \times 302$ grey matrix, as partially shown in equation (1). Finally, by calculating the average grey value of the matrix, the internal damage of concrete was quantified and characterized:

$$
C=\left[\begin{array}{cccccccc}
1 & 255 & 0 & 85 & \ldots & 0 & 0 & 255 \\
2 & 22 & 0 & 65 & \ldots & 0 & 0 & 0 \\
3 & 65 & 65 & 89 & \ldots & 0 & 0 & 0 \\
\vdots & \vdots & \vdots & \vdots & \ddots & \vdots & \vdots & \vdots \\
300 & 65 & 65 & 42 & \ldots & 0 & 0 & 0 \\
301 & 35 & 0 & 65 & \ldots & 0 & 0 & 0 \\
302 & 255 & 35 & 0 & \ldots & 0 & 0 & 255 \\
& 1 & 2 & 3 & \ldots & 300 & 301 & 302
\end{array}\right] .
$$

$3 \mathrm{D}$ reconstruction imaging result and thirteen typical CT slices along the radial direction of the jet were obtained, as shown in Figure 4. By calculating the average grey values of the thirteen CT slices, the variation law of the average grey values along the radial direction of the jet was obtained, as shown in Figure 5. It is evident that the average grey value 


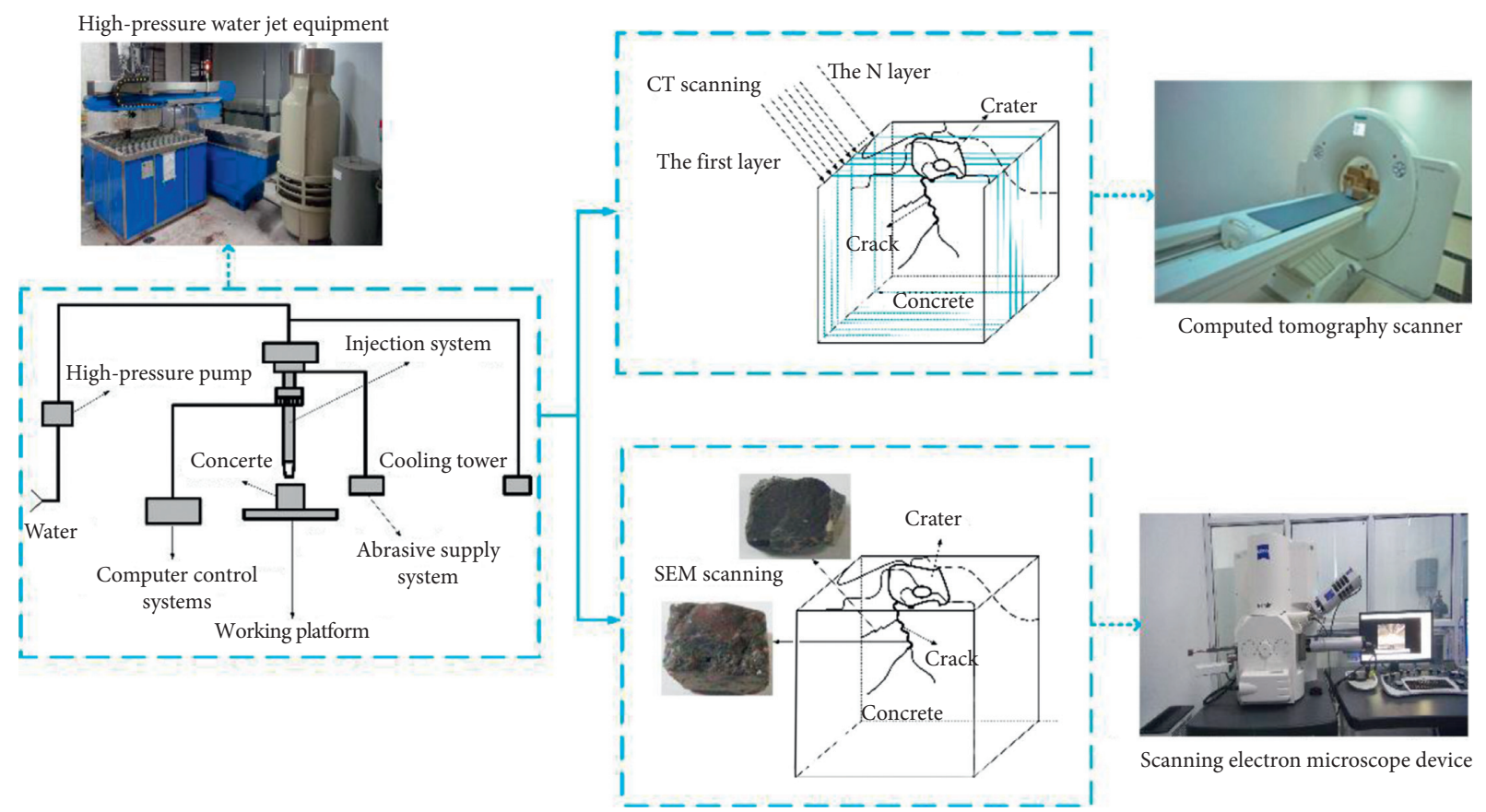

Figure 1: The experimental equipment and fundamental procedure.

TABle 2: Mechanical properties of the concrete specimens.

\begin{tabular}{lccc}
\hline Compressive strength $(\mathrm{MPa})$ & Tensile strength $(\mathrm{MPa})$ & Modulus of elasticity $(\mathrm{MPa})$ & Poisson's ratio \\
\hline 30 & 2.4 & $3 \times 10^{4}$ & 0.3 \\
\hline
\end{tabular}

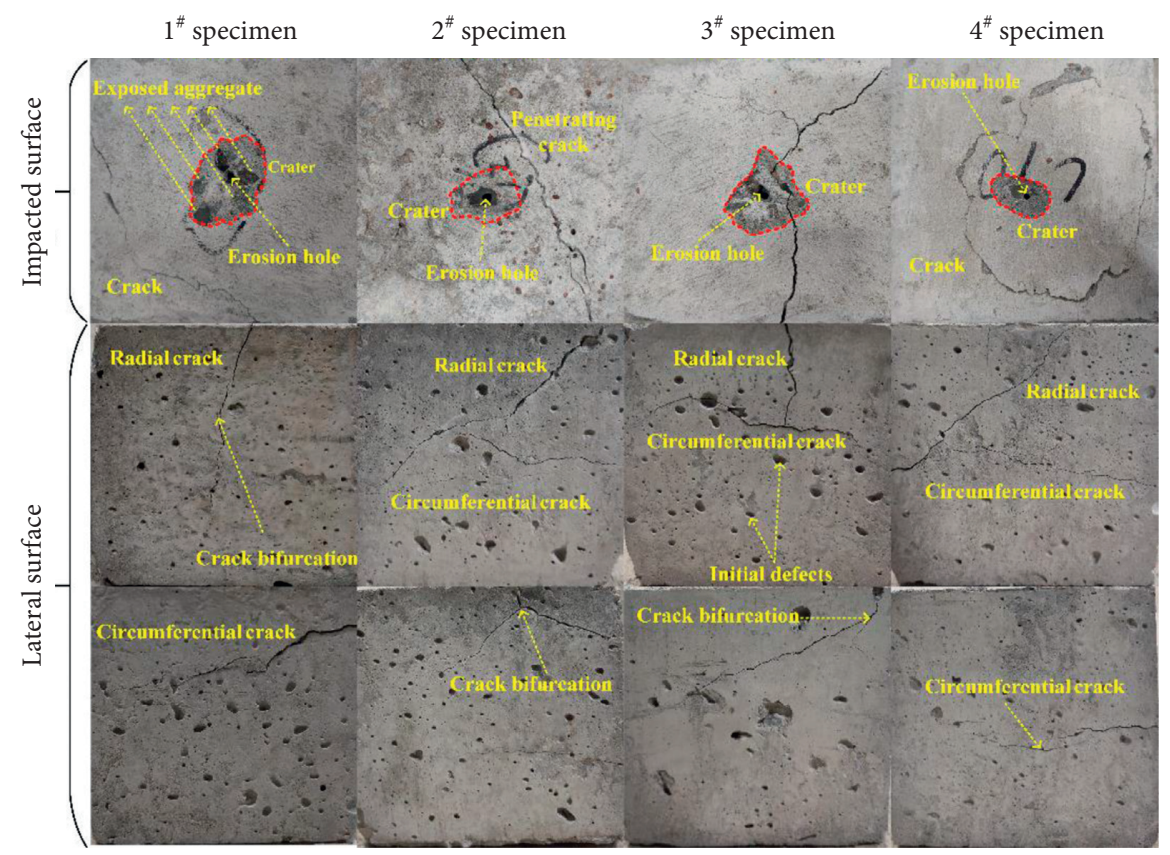

Figure 2: External morphology of concrete after AWJ impact. 


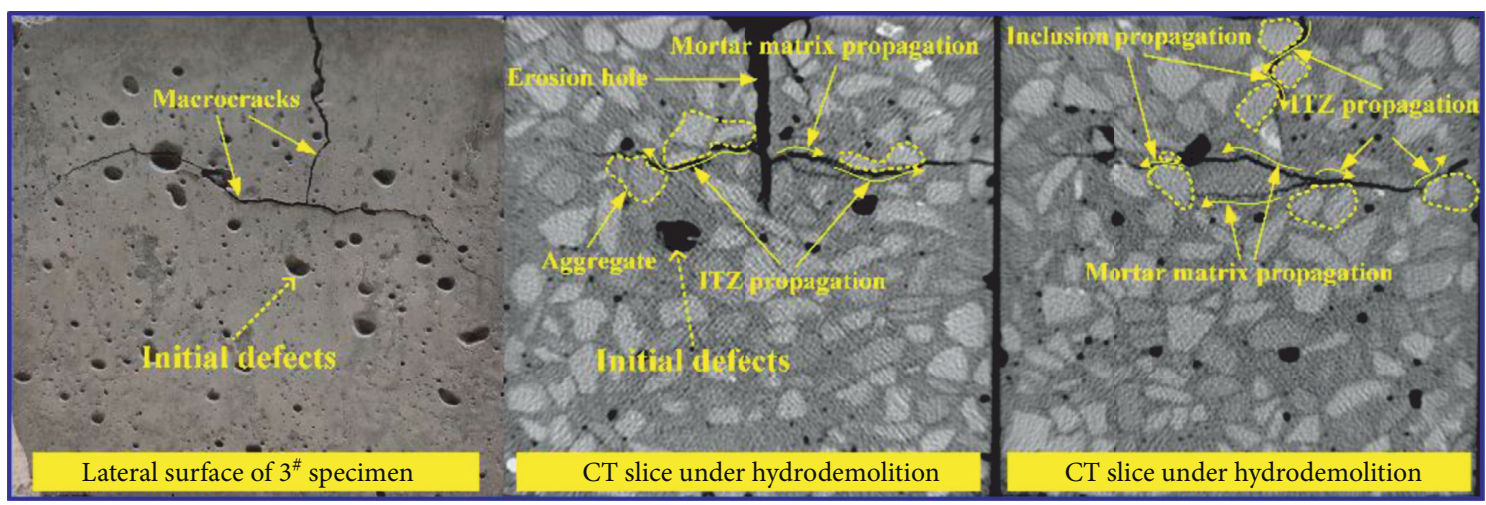

FIGURE 3: Crack propagation paths in the interior of concrete.

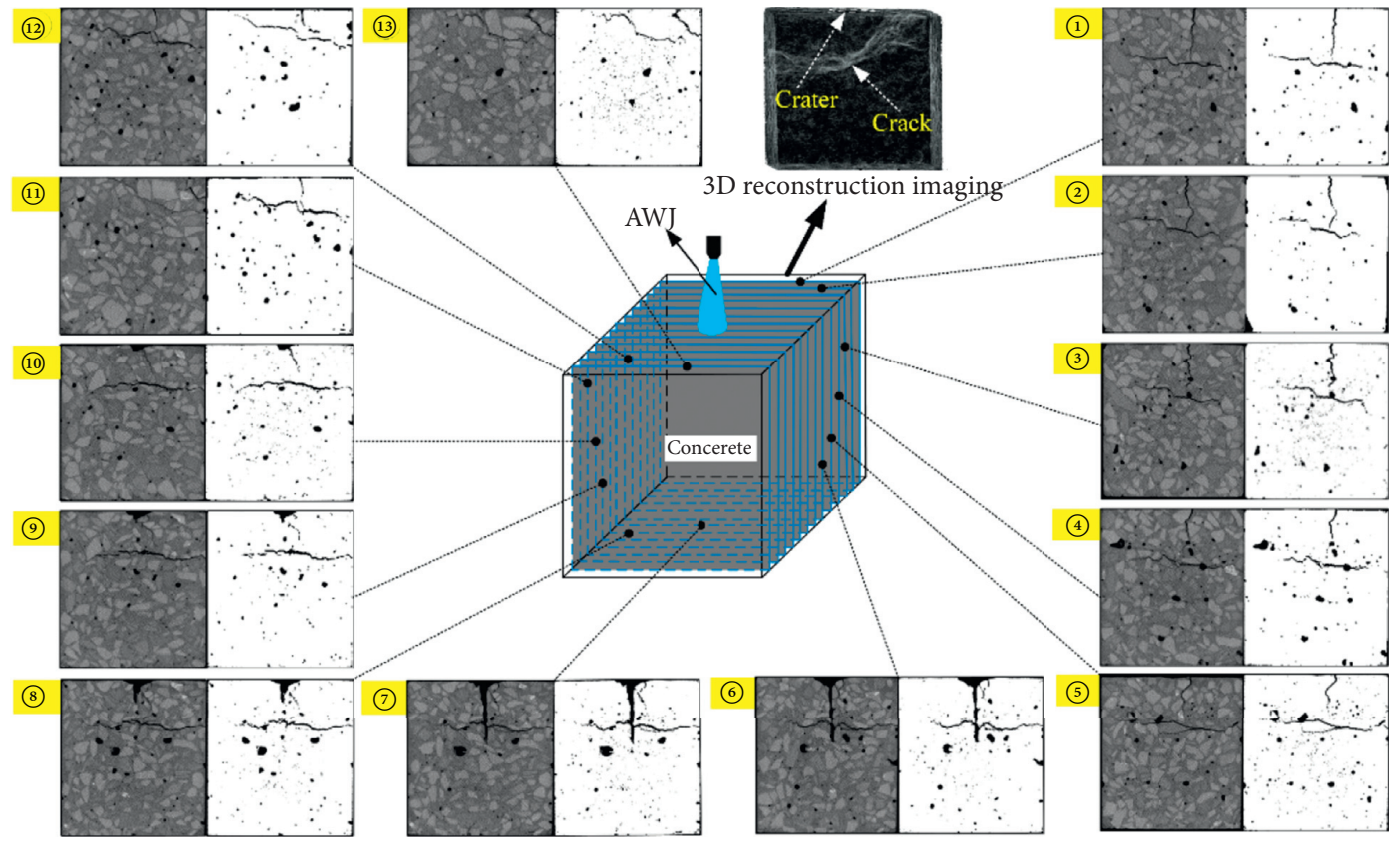

FIGURE 4: Distribution of the CT slices and scanning results.

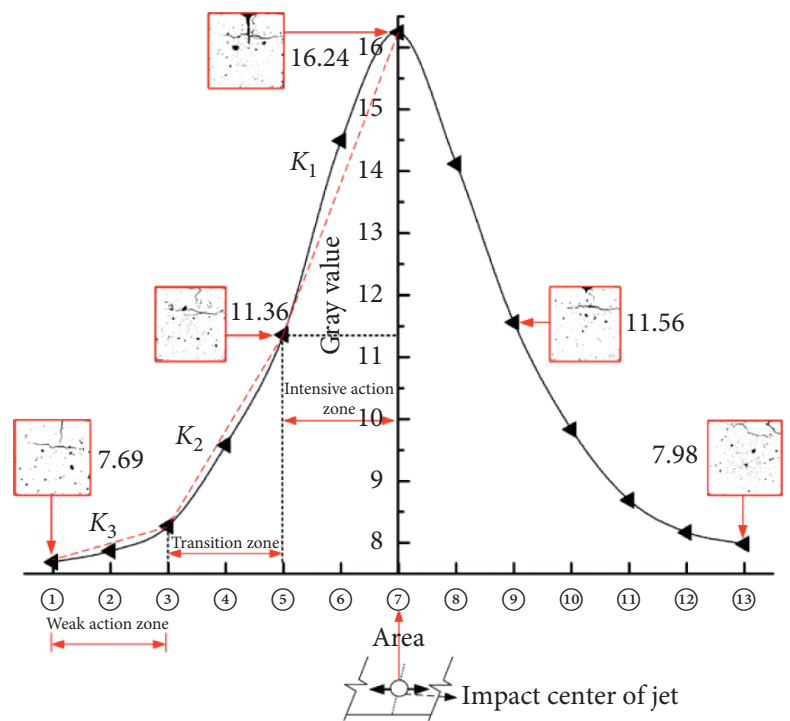

Figure 5: Variation curve of the average grey value of CT slices. 
nonlinearly decreased as the distance between the analysed CT slice and the impacted centre of the jet increased. Due to the symmetry of AWJ impact, seven slices from "(1)" to "(7)" were used for a typical analysis. It can be found that the CT slice in the impacted centre exhibited the maximum grey value, representing the most severe damage. The zone with a grey value that decreased at an average rate of $K_{1}=0.488$ could be called the intensive action zone of AWJ impact. The average grey value decreased at a rate of $K_{2}=0.309$ in the transition zone of AWJ impact due to the weakened crushing effect of the jet. The grey value decreased at a rate of $K_{3}=0.058$ in the weak action zone of AWJ impact. In total, the intense action zone of the jet is limited to the vicinity of the jet in a range that is approximately 20 times the jet diameter, the transition zone is in the range of 20 to 40 times the jet diameter, and the weak action zone of the jet is outside the range of 40 times the jet diameter.

Though the variations in the jet parameters have certain effects on the fragmentation feature of concrete impacted by AWJ, the fragmentation pattern of concrete still exhibits many similarities. The general failure characteristics, crack extension law, and spatial distribution of the abovementioned damage can be analysed to evaluate the crack distribution feature during concrete hydrodemolition and predict the fragmentation degree and damage dimension in concrete under AWJ impact, which can improve the application level of AWJ breaking technology in concrete structure maintenance and emergency demolition in accidents.

\section{Removal Mechanism of AWJ Impact}

The microstructure of broken concrete can be observed by SEM. In this research, the removal mechanism of the AWJ impact was explored by analysing the microstructure characteristics of concrete in detail.

In SEM images, the aggregate, mortar, and ITZ parts present different morphological characteristics. The aggregate has a dense structure, massive or flake morphology, no obvious granularity, and less porosity. The mortar shows a loose and porous structure, with granular distribution. And the ITZ part is a weak structure, which is located at the junction of aggregate structure and mortar structure. Therefore, this paper analysed the microscopic morphology characteristics of aggregate, mortar, and ITZ.

4.1. Aggregate Part. Figure 6 presents typical SEM images of the aggregate fracture sections subjected to the two types of jet impact. At the magnification of 5000x, under AWJ impact, "cliff-like" failure with grooves having different depths and distorted "lip-like" fracture could be recognized in the aggregate part. However, under PWJ impact, the aggregate part had a higher degree of overall crushing, with an obviously uneven fracture surface, and there were peeled blocks and broken particles distributed at the bottom of the section.

The abrasive particles are much denser than the water used in AWJ impact, and the abrasive particles have sharp edges and angularities, so AWJ technology has an intense grinding capability. The strong action of abrasives causes enormous deformation and distortion in the contact area of the aggregate and abrasives, thus forming distorted "lip-like" fracture. Simultaneously, the cutting action of abrasives induces the relative shear slip of aggregates, which leads to the overall "cliff-like" damage (Figure $7(\mathrm{a})$ ).

Unlike AWJ, due to the high density and diffusion coefficient of high-pressure water in PWJ, strong water hammer compression is produced in the liquid-solid contact centre (Figure 8(a)), which generates the tension effect in concrete. When the tensile stress exceeds the dynamic tensile strength, cracks form in concrete. Besides, PWJ can cause shear failure at the contact edge of the jet and concrete. Once the abovementioned damage initiates, the high-speed fluid enters the cracks in an instant, and the strong rush and delivery action of the fluid cause the block to be peeled off and carried away, leading to the scattering of broken particles on the fracture section (Figure 7(b)).

4.2. Matrix Part. The SEM image in Figure 8 is obtained at a magnification of $1000 \mathrm{x}$ and clearly shows that, under AWJ impact, the mortar matrix fracture section was relatively flat, with apparent severe abrasion signs, and it can also be observed that abrasion particles were scattered on the fracture section. In contrast, PWJ impact generated massive microcracks and microholes on the uneven fracture section of the mortar matrix. The morphology differences are mainly attributed to the failure mechanism of the two types of jets. Under AWJ impact, the damage of the mortar matrix is mainly caused by the impact and grinding effect of abrasives, so a flat fracture section with marked abrasion signs forms. However, the strong tensile and water wedge action of PWJ cause the mortar matrix to split, producing more microcracks, and the scouring effect of the high-speed water makes the surface irregular.

In addition, at a magnification of $200 x$, a concave pit appeared on the fracture section of the mortar matrix subjected to AWJ impact, as shown in Figure 9. By comparing the magnitude order of the pit to the abrasive particles, the diameter of the abrasives ( 80 mesh, $178 \mu \mathrm{m})$ was close to that of the pit (approximately $180 \mu \mathrm{m}$ ), so it can be inferred that the pit was possibly caused by the erosion of the abrasive particles.

4.3. ITZ Part. Under the two types of jets impact, ITZ also showed different micromorphologies. According to Figure 10, under AWJ impact, it can be noted that the mortar matrix part and aggregate part were basically well connected through ITZ, yet there was a distinct crack formed in ITZ under PWJ impact. It is well-known that the water-gel ratio in ITZ is higher than that in the mortar matrix part, and the existence of aggregates affects the water hardening of the cement particles near the aggregates [29], resulting in more microcracks in ITZ. For AWJ impact, a large amount of energy is derived from the abrasive particles, leading to the intensifying of the grinding of abrasives and the weakening of the water permeability. Thus, it is relatively hard to form 


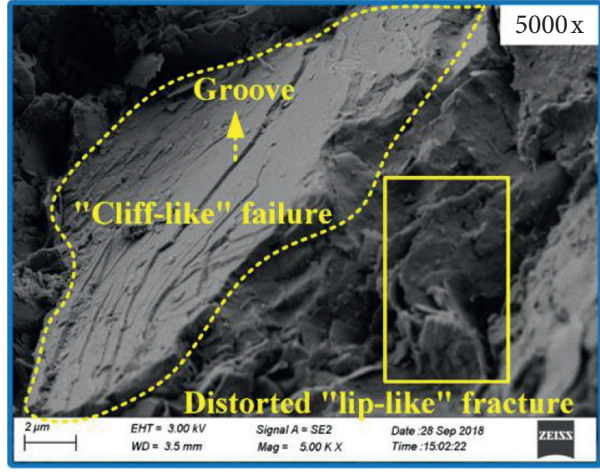

(a)

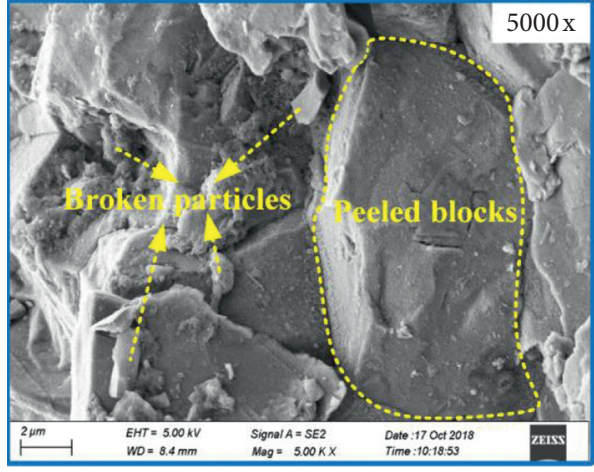

(b)

FIGURE 6: Typical SEM scanning images of the aggregate sections. (a) AWJ impact; (b) PWJ impact.

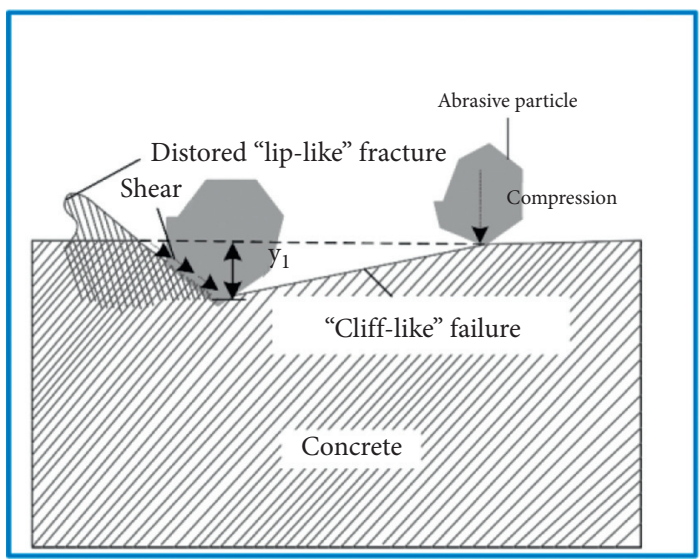

(a)

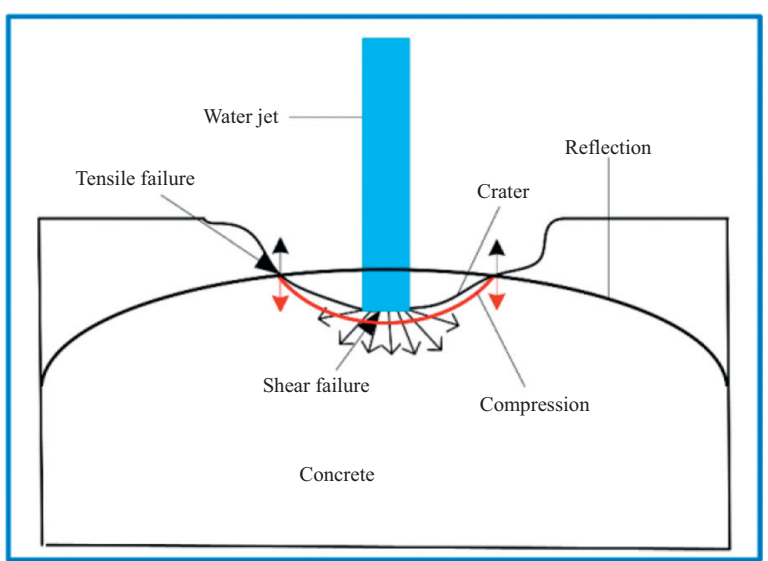

(b)

Figure 7: Action mechanism of the PWJ and AWJ crushing of concrete. (a) Action feature of the abrasive particles [2]. (b) The action property of PWJ.

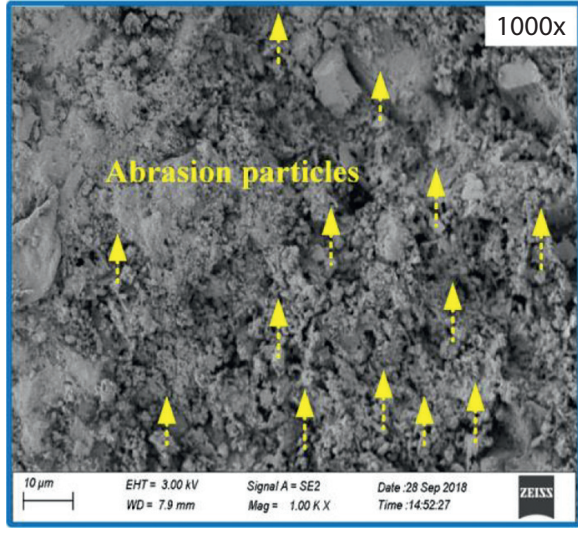

(a)

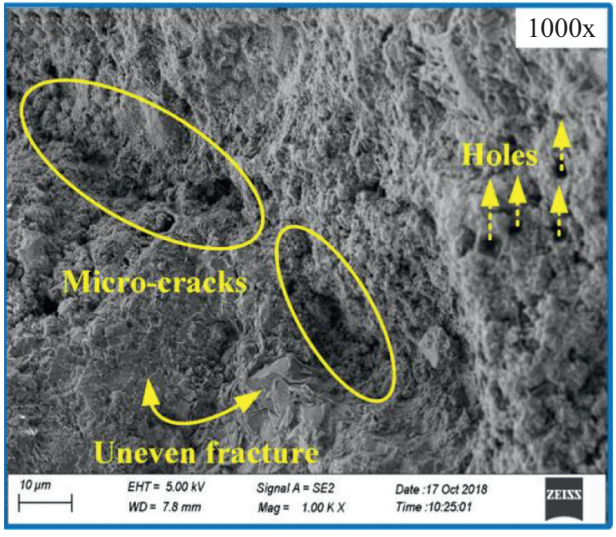

(b)

Figure 8: Typical SEM images of the mortar matrix sections. (a) AWJ impact; (b) PWJ impact.

the obvious long cracks in ITZ under AWJ impact. In contrast, for PWJ impact, all the energy is provided by water, and therefore, the intense impact force of PWJ has a strong water wedge effect on concrete. Under the action of the water wedge, water can easily penetrate the microcracks and drive the microcracks to expand into a long crack in ITZ. 


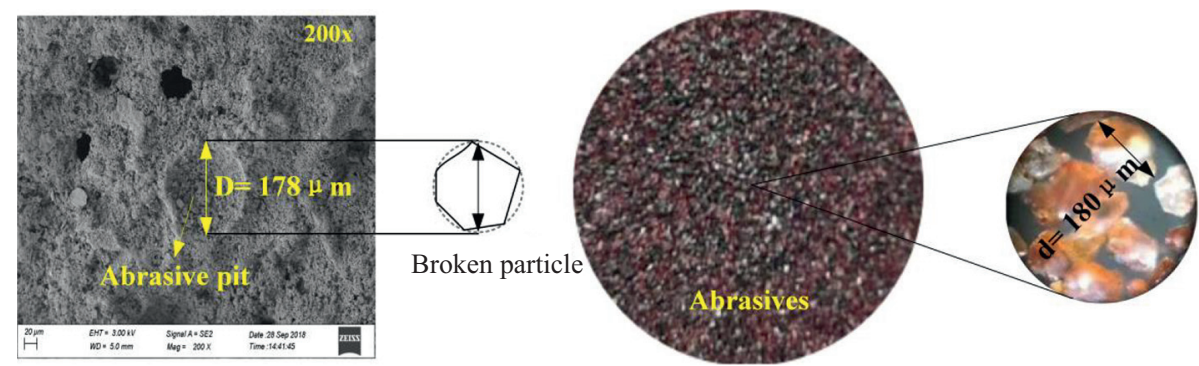

FIgURE 9: The magnitude order comparison of the abrasive pits and abrasive particles.

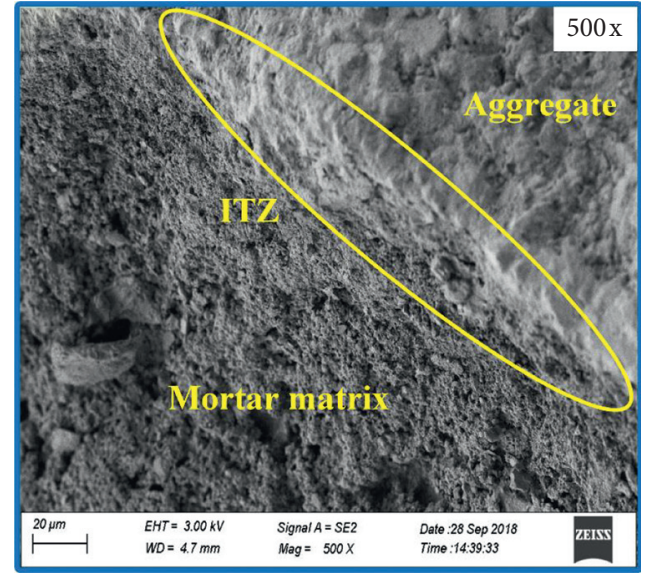

(a)

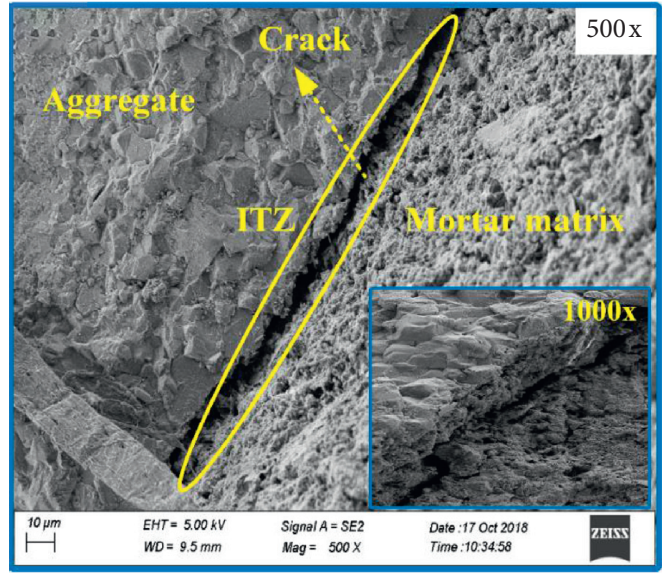

(b)

Figure 10: Typical SEM images of ITZ section. (a) AWJ impact; (b) PWJ impact.

\section{Conclusions}

Based on the CT and SEM, this paper studied the failure characteristics, crack extension law, spatial distribution of damage, and removal mechanism of concrete under AWJ impact. In practical applications, the results can help to speculate the crack distribution feature during concrete hydrodemolition, predict the damage dimension in concrete, and evaluate the overall fragmentation of concrete under AWJ impact, which will promote the application level of AWJ in the maintenance and repair of concrete structures as well as in emergency demolition. The main conclusions of the research are summarized as follows:

(1) The failure analyses of four concrete samples subjected to AWJ impact show that similar craters usually represent irregular shapes with rough walls and exposed aggregates. Cracks penetrating across the impacted surface appear near the craters, causing macrodamage. Some internal cracks and the cracks on the impacted surface propagated to the lateral surface, forming a network of radial cracks and circumferential cracks intersecting each other. Furthermore, using CT scans to explore the crack propagation law indicates that the cracks mainly extend over ITZ due to its weak mechanical properties, which have less effect on the strength of the undamaged zone of concrete.

(2) By the binarization processing and greyscale processing of CT images, this paper further demonstrates the spatial distribution of concrete damage. The result shows that the CT slice in the impacted centre has a maximum grey value representing the most severe damage. In addition, the intense action zone of the jet is limited to the vicinity of the jet in the range of approximately 20 times the jet diameter, the transition zone in the range of 20 to 40 times the jet diameter, and the weak action zone of the jet outside the range of 40 times the jet diameter.

(3) SEM scans and a comparison of the impact performance obtained by PWJ impact were performed to study the fracture morphology of different components of concrete and revealed the removal mechanism of AWJ impact. It was found that abrasive particles will cause "cliff-like" failure with grooves having different depths and distorted "liplike" fracture in the aggregate part. There are obvious abrasion particles and severe abrasion signs in the matrix part. It is comparatively difficult to form obvious long cracks in ITZ, partly due to the weakened water wedge effect. 


\section{Data Availability}

The data used to support the findings of this study are included within the article.

\section{Conflicts of Interest}

The authors declare no conflicts of interest.

\section{Acknowledgments}

This work was supported by the National Natural Science Foundation of China (Grant no. 51608082), the General Fund of Chongqing Natural Science Foundation (Grant no. cstc2020jcyj-msxm3094), and the China Postdoctoral Science Foundation (Grants nos. 2020M683257 and 2019M652904).

\section{References}

[1] M. Sánchez, P. Faria, L. Ferrara et al., "External treatments for the preventive repair of existing constructions: a review," Construction and Building Materials, vol. 193, pp. 435-452, 2018.

[2] A. W. Momber and R. Kovacevic, Principles of abrasive water jet machining, pp. 90-93, Springer, London, UK, 1998.

[3] E. C. Lohrey, Use of Hydrodemolition to Remove Deteriorated Concrete from Bridge Decks, pp. 83-89, Transportation Research Board, Olympia, WA, USA, 1995, http://worldcat.org/ isbn/0309061547.

[4] A. W. Momber, "Water jet applications in construction engineering," Journal of Psychiatric Research, vol. 58, no. 8, pp. 161-166, 1998.

[5] C. Shet, X. Deng, and A. Bayoumi, "Finite element simulation of high-pressure water-jet assisted metal cutting," International Journal of Mechanical Sciences, vol. 45, no. 6-7, pp. 1201-1228, 2003.

[6] Y. Lu, Y. Liu, X. Li, and Y. Kang, "A new method of drilling long boreholes in low permeability coal by improving its permeability," International Journal of Coal Geology, vol. 84, no. 2, pp. 94-102, 2010.

[7] Z. Wu, F. Yu, P. Zhang, and X. Liu, "Micro-mechanism study on rock breaking behavior under water jet impact using coupled SPH-FEM/DEM method with Voronoi grains," Engineering Analysis with Boundary Elements, vol. 108, pp. 472-483, 2019.

[8] F. Ren, T. Fang, and X. Cheng, "Study on rock damage and failure depth under particle water-jet coupling impact," International Journal of Impact Engineering, vol. 139, 2020.

[9] X. Wu, Z. Huang, X. Dai, H. Song, and S. Zhang, "Thermocoupled FSI analysis of LN2 jet impinging on hot dry rock," Applied Thermal Engineering, vol. 165, 2020.

[10] D. Arola and M. Ramulu, "Material removal in abrasive waterjet machining of metals Surface integrity and texture," Wear, vol. 210, no. 1-2, pp. 50-58, 1997.

[11] Y. Hu, Y. Kang, X.-C. Wang et al., "Mechanism and experimental investigation of ultra high pressure water jet on rubber cutting," International Journal of Precision Engineering and Manufacturing, vol. 15, no. 9, pp. 1973-1978, 2014.

[12] F. P. Bowden and J. H. Brunton, "The deformation of solids by liquid impact at supersonic speeds," Proceedings of the Royal Society A: Mathematical, Physical and Engineering Sciences, vol. 263, no. 1315, pp. 433-450, 1961.
[13] R. Kovacevic, H.-S. Kwak, and R. S. Mohan, "Acoustic emission sensing as a tool for understanding the mechanisms of abrasive water jet drilling of difficult-to-machine materials," Proceedings of the Institution of Mechanical Engineers, Part B: Journal of Engineering Manufacture, vol. 212, no. 1, pp. 45-58, 1998.

[14] H. Hocheng and C. H. Weng, "Hydraulic erosion of concrete by a submerged jet," Journal of Materials Engineering and Performance, vol. 11, no. 3, pp. 256-261, 2002.

[15] A. W. Momber, "Deformation and fracture of rocks due to high-speed liquid impingement," International Journal of Fracture, vol. 130, no. 3, pp. 683-704, 2004.

[16] S. Dehkhoda and M. Hood, "The internal failure of rock samples subjected to pulsed water jet impacts," International Journal of Rock Mechanics and Mining Sciences, vol. 66, pp. 91-96, 2014.

[17] M. A. Vicente, J. Mínguez, and D. C. González, “Computed tomography scanning of the internal microstructure, crack mechanisms, and structural behavior of fiber-reinforced concrete under static and cyclic bending test," International Journal of Fatigue, vol. 121, 2018.

[18] A. W. Momber, "Deformation and fracture of rocks loaded with spherical indenters," International Journal of Fracture, vol. 125, no. 3-4, pp. 263-279, 2004.

[19] L. F. Fan, J. W. Gao, Z. J. Wu, S. Q. Yang, and G. W. Ma, “An investigation of thermal effects on micro-properties of granite by X-ray CT technique," Applied Thermal Engineering, vol. 140, pp. 505-519, 2018.

[20] L. Fan, J. Gao, X. Du, and Z. Wu, "Spatial gradient distributions of thermal shock-induced damage to granite," Journal of Rock Mechanics and Geotechnical Engineering, vol. 12, no. 5, pp. 917-926, 2020.

[21] L. F. Fan, J. W. Gao, and X. L. Du, "Thermal cycling effects on micro-property variation of granite by a spatial micro-observation," Rock Mechanics and Rock Engineering, vol. 53, no. 6, pp. 2921-2928, 2020.

[22] X. Sun, X. Li, B. Zheng, J. He, and T. Mao, "Study on the progressive fracturing in soil and rock mixture under uniaxial compression conditions by CT scanning," Engineering Geology, vol. 279, no. 4, 2020.

[23] L. F. Fan, Z. J. Wu, Z. Wan, and J. W. Gao, "Experimental investigation of thermal effects on dynamic behavior of granite," Applied Thermal Engineering, vol. 125, pp. 94-103, 2017.

[24] I. Blonskaya, O. Kristavchuk, A. Nechaev, O. Orelovich, O. Polezhaeva, and P. Apel, "Observation of latent ion tracks in semicrystalline polymers by scanning electron microscopy," Journal of Applied Polymer Science, vol. 138, 2021.

[25] Z. Zhao, H. Jing, X. Shi, J. Wu, and Q. Yin, "Experimental investigation on fracture behaviors and acoustic emission characteristics of sandstone under different strain rates," Environmental Earth Sciences, vol. 80, no. 3, 2021.

[26] B. Bera, S. K. Mitra, and D. Vick, "Understanding the micro structure of Berea Sandstone by the simultaneous use of micro-computed tomography (micro-CT) and focused ion beam-scanning electron microscopy (FIB-SEM)," Micron, vol. 42, no. 5, pp. 412-418, 2011.

[27] B. Rémi, O. Caty, V. Mazars et al., "In-situ tensile tests under SEM and X-ray computed micro-tomography aimed at studying a self-healing matrix composite submitted to different thermomechanical cycles," Journal of the European Ceramic Society, vol. 37, no. 10, pp. 3471-3474, 2017.

[28] M. Heng, S. C. Tian, G. S. Li, H. K. Ge, H. L. Liao, and Z. K. Li, "Shale rock fragmentation behavior sand their mechanics by 
high pressure waterjet impinging," Scientia Sinica (Physica, Mechanica \& Astronomica), vol. 47, no. 11, pp. 99-106, 2017.

[29] J. P. Ollivier, J. C. Maso, and B. Bourdette, "Interfacial transition zone in concrete," Advanced Cement Based Materials, vol. 2, no. 1, pp. 30-38, 1995. 